\title{
DEGENERATED HUMAN INTERVERTEBRAL DISCS CONTAIN AUTOANTIBODIES AGAINST EXTRACELLULAR MATRIX PROTEINS
}

\author{
S. Capossela ${ }^{1}$, P. Schläfli ${ }^{1}$, A. Bertolo ${ }^{1}$, T. Janner ${ }^{1}$, B. M. Stadler ${ }^{2}$, T. Pötzel ${ }^{3}$, M. Baur ${ }^{4}$ and J. V. Stoyanov ${ }^{1, *}$
}

${ }^{1}$ Biomedical Laboratories, Swiss Paraplegic Research, Nottwil, Switzerland

${ }^{2}$ University Institute of Immunology, University of Bern, Bern, Switzerland ${ }^{3}$ Swiss Paraplegic Center, Nottwil, Switzerland

${ }^{4}$ Cantonal Hospital of Lucerne, Lucerne, Switzerland

\begin{abstract}
Degeneration of intervertebral discs (IVDs) is associated with back pain and elevated levels of inflammatory cells. It has been hypothesised that discogenic pain is a direct result of vascular and neural ingrowth along annulus fissures, which may expose the avascular nucleus pulposus (NP) to the systemic circulation and induce an autoimmune reaction. In this study, we confirmed our previous observation of antibodies in human degenerated and posttraumatic IVDs cultured in vitro. We hypothesised that the presence of antibodies was due to an autoimmune reaction against specific proteins of the disc. Furthermore we identified antigens which possibly trigger an autoimmune response in degenerative disc diseases. We demonstrated that degenerated and post-traumatic IVDs contain IgG antibodies against typical extracellular proteins of the disc, particularly proteins of the NP. We identified IgGs against collagen type II and aggrecan, confirming an autoimmune reaction against the normally immune privileged NP. We also found specific IgGs against collagens types I and V, but not against collagen type III. In conclusion, this study confirmed the association between disc degeneration and autoimmunity, and may open the avenue for future studies on developing prognostic, diagnostic and therapymonitoring markers for degenerative disc diseases.
\end{abstract}

Keywords: Intervertebral disc, nucleus pulposus, annulus fibrosus, extracellular matrix.

\footnotetext{
*Address for correspondence:

Jivko V. Stoyanov, Ph.D

Swiss Paraplegic Research

CH-6207 Nottwil

Switzerland
}

Telephone Number: +41 41-939-6635

FAX Number: +41 41-939-6640

E-mail: jivko.stoyanov@paraplegie.ch

\section{Introduction}

The intervertebral disc (IVD) is the largest avascular structure in the human body. It is composed of an outer annulus fibrosus (AF), made up of concentric lamellae rich in collagen type $\mathrm{I}$, and a central gelatinous nucleus pulposus (NP), rich in proteoglycans and collagen type II (Raj, 2008). Collagens type I and type II give tensile strength and anchor the disc tissue to the bone. On the other hand, tissue hydration of the disc is sustained by the major proteoglycan, aggrecan, which with the help of its chondroitin and keratin sulphate chains, maintains the osmotic pressure of the disc (Urban and Roberts, 2003).

With increasing age and degeneration, the disc becomes disorganised: annular lamellae become irregular (Raj, 2008) and aggrecan degradation results in a loss of hydration, which leads to progressive loss of space between vertebrae (Urban and Roberts, 2003). The fall in concentration of aggrecan allows penetration of large molecules into the disc, such as growth factors and cytokines (Raj, 2008). Molecular mediators of inflammation are present in pathologic disc tissues. Interleukin-1 beta (IL-1 $\beta$ ) and tumour necrosis factor alpha (TNF- $\alpha$ ) (Le Maitre et al., 2007), IL-6 and IL-8 (Burke et al., 2002), IL-17 and IFN $\gamma$ (Shamji et al., 2010) may correlate with the grade of degeneration and have been linked to back pain. Additionally, aggrecan in the intervertebral disc inhibits nerve growth and repels sensory nerves, suggesting that loss of aggrecan can cause vascularisation and innervation of the disc (Johnson et $a l ., 2002)$. Structural changes and increased vascular and neural ingrowth in degenerated discs have been closely associated with chronic back pain (Stefanakis et al., 2012). Low back pain is a very common multifactor condition in the general population; it becomes chronic in $30 \%$ of cases and causes great economic impact, due to loss of productivity and increased health care costs (Strong et al., 2013). Back pain is related to ageing, mechanical stresses (Adams, 2004) and genetic predisposition (Patel et al., 2011), and it is attributed to disc degeneration in around $40 \%$ of patients (Rodrigues-Pinto et al., 2013). Pathogenesis of chronic low back pain has been also hypothesised to have an autoimmune component (Bobechko and Hirsch, 1965; Kim et al., 1981). Healthy IVDs are avascular and NP is contained within the AF, hidden from the immune system. Vascularisation along the annular fissures exposes the degenerated disc to contact with cells of the immune system, and epitopes or degradation products of disc proteins may trigger an autoimmune reaction (Geiss et al., 2007). The ability of NP to induce an inflammatory response and autoimmune 
reaction has been shown in dogs (McCarron et al., 1987), pigs (Geiss et al., 2007) rabbits (Bobechko and Hirsch, 1965), and the presence of IgGs has been identified in canine NP by ELISA assay (Pennington et al., 1988). Murai et al. (2010) have also demonstrated in rats, that nondegenerated NP cells in vitro and transplanted NP tissues in vivo, can be recognised by macrophages and natural killer cells (NK), which may have an immunological function in the early phase of disc herniation. Patients with prolapsed IVD and sciatica had an increased disc to serum antibody ratio, measured by nephelometry (Spiliopoulou et al., 1994), while immunohistochemistry studies have detected antigen-antibody complexes in the pericellular space of human herniated discs (Satoh et al., 1999). Deposits of immunoglobulin $G$ and $M$ in human disc herniated tissue suggests a correlation between inflammation and autoimmune response (Habtemariam et al., 1996). Furthermore, we have recently shown that significant amounts of IgG antibodies remain in human degenerated and post-traumatic IVDs, despite thorough washing after discectomy (Bertolo et al., 2011). Until now however, there are no studies in humans, which show the specificity of the antibodies present in the disc.

In this article we want to pose the question what kind of antibodies are produced during the degeneration of the disc. We focused on the hypothesis that antibodies present in degenerated IVDs are against major proteins of the disc, such as collagen type I and type II or minor components, such as collagen type III and type V. Considering that disc degeneration is related to a decrease in proteoglycans content, we included aggrecan and native proteoglycan protein extracts as other putative targets of the autoimmune response. To test the hypothesis, by immunohistochemistry and immunoblotting techniques, we analysed human degenerated and post-traumatic IVD fragments, as well as media collected from cultured in vitro discs, for the presence of disc specific IgGs and used bovine caudal discs as healthy negative controls.

\section{Materials and Methods}

\section{Intervertebral disc fragment harvest}

Human degenerated and post-traumatic IVDs (AF and NP separately) were obtained from patients $(n=20)$ undergoing surgical intervention, after informed consent and approval by ethics committee of canton Luzern (collected samples are listed in Table 1). IVD samples were immediately harvested in Hank's Balanced Salt Solution (Gibco - LuBioScience GmbH, Lucerne, Switzerland) and the solution was collected after 1-3 h (disc medium day $0)$. Samples were washed 3-4 times in phosphate-buffered saline (PBS) to eliminate residual blood, and cultured in DMEM/F12 + Gluta-MAX, supplemented with $10 \%$ FBS, (100 units $/ \mathrm{mL}$ ) penicillin / $(100 \mu \mathrm{g} / \mathrm{mL})$ streptomycin (all Gibco) and $2.5 \mu \mathrm{g} / \mathrm{mL}$ amphotericin B (Sigma - Fluka Chemie $\mathrm{GmbH}$, Buchs, Switzerland) at $37{ }^{\circ} \mathrm{C}$ and $5 \% \mathrm{CO}_{2}$. After three days, disc medium of thoroughly washed disc fragments cultured in vitro was collected (disc medium day 3 ). Remaining fragments were washed three times in PBS and frozen at $-80{ }^{\circ} \mathrm{C}$ for storage or embedded in Tissue-

Table 1. Demographic details of annulus fibrosus and nucleus pulposus donors.

\begin{tabular}{|c|c|c|c|c|}
\hline Sample & Sex & $\begin{array}{c}\text { Donor's age } \\
\text { (Years) }\end{array}$ & $\begin{array}{c}\text { Thompson } \\
\text { Grading Scale }\end{array}$ & Type of operation \\
\hline 1 & F & 71 & III & DDD. Discectomy L4/5 \\
\hline 2 & M & 41 & III & DDD. Discectomy L5/S1 \\
\hline 3 & M & 65 & III & DDD. Discectomy L3/4-L4/5 \\
\hline 4 & M & 65 & IVa & Trauma. Discectomy Th11/12/L1 \\
\hline 5 & M & 49 & III & DDD. Discectomy L5/S1 \\
\hline 6 & M & 57 & III & Trauma. Discectomy C5/C6 \\
\hline 7 & F & 40 & IV & DDD. Discectomy L5/S1 \\
\hline 8 & F & 59 & III & DDD. Discectomy L4/5 \\
\hline 9 & M & 44 & II & Trauma. Discectomy L3/4/5 \\
\hline 10 & M & 67 & III & DDD. Discectomy L4/5 \\
\hline 11 & M & 58 & III & DDD. Discectomy L5/S1 \\
\hline 12 & F & 76 & IV & DDD. Discectomy L4/5-L3/4 \\
\hline 13 & M & 31 & IV & DDD. Discectomy L4-L5-S1 \\
\hline 14 & F & 59 & III & DDD. Discectomy L4/5 \\
\hline 15 & F & 70 & III & DDD. Discectomy L4/5 \\
\hline 16 & F & 51 & IV & DDD. Discectomy L2-5 \\
\hline 17 & F & 73 & IV & DDD. Discectomy C4/5/6/7 \\
\hline 18 & M & 36 & III & DDD. Discectomy L5/S1 \\
\hline 19 & M & 41 & III & DDD. Discectomy L4/5 \\
\hline 20 & M & 41 & III & DDD. Discectomy L3/4 \\
\hline
\end{tabular}

Average age $=55 \pm 14$ years old; DDD $=$ Degenerative Disc Disease. 
Tek (Sakura - Sysmex Suisse AG, Horgen, Switzerland) for immunohistochemical analysis.

As healthy controls, we isolated discs from bovine tail, obtained from a local slaughterhouse. Bovine discs were dissected and nucleus pulposus (bNP) was separated from inner and outer annulus fibrosus (bAF).

\section{RNA extraction and gene expression of IVD fragments \\ IVD fragments $(n=10)$, frozen at $-80^{\circ} \mathrm{C}$, were pulverised} on dry ice in a stainless steel mortar and total RNA was extracted by Aurum Total Mini Kit (Bio Rad, Reinach, Switzerland), following the manufacturer's instructions. One $\mu \mathrm{g}$ of total RNA was used for synthesis of $\mathrm{cDNA}$ (SuperScript VILO cDNA Synthesis Kit, Invitrogen LuBioScience GmbH, Lucerne, Switzerland), followed by dilution (1:5) with ultrapure water. Template cDNA $(5 \mu \mathrm{L})$ was mixed with PCR reaction solution (IQ SYBR Green Supermix, BioRad) containing $0.25 \mu \mathrm{M}$ specific primers, listed in Table 2. Final volume of $25 \mu \mathrm{L}$ was placed in 96-well plates (BioRad) and amplified according to the following settings: denaturation at $95{ }^{\circ} \mathrm{C}$ for $3 \mathrm{~min}(1$ cycle); $95^{\circ} \mathrm{C}$ for $15 \mathrm{~s}, 64{ }^{\circ} \mathrm{C}$ for $20 \mathrm{~s}$ and $72{ }^{\circ} \mathrm{C}$ for $20 \mathrm{~s}$ (40 amplification cycles), followed by a melting curve analysis. Specific products (GAPDH, IL-17A, IL-6, and IL-8) were amplified by a quantitative PCR (CFX96 ${ }^{\mathrm{TM}}$ Real Time System, BioRad) in triplicates. The results were normalised to the expression of GAPDH. The correct products of PCR were validated on $2.5 \%$ agarose gel with EZ Load 100 bp Molecular Ruler (BioRad) and detected with Gene Genius Bio Imaging System (Syngene - Biolabo Scientific Instruments SA, Chatel St Denis, Switzerland).

\section{Protein extraction from IVD fragments}

IVD fragments $(n=10)$, frozen at $-80^{\circ} \mathrm{C}$, were pulverised on dry ice in a stainless steel mortar, and lysed with $500 \mu \mathrm{L}$ of CelLytic MT Mammalian Tissue Lysis Extraction Reagent (Sigma). To prevent degradation, Protease Inhibitor Cocktail (Sigma) was added and lysates were homogenised using a Dispomix device (Axonlab, Baden, Switzerland). After $15 \mathrm{~min}$ incubation at room temperature, lysates were centrifuged at $17000 \mathrm{~g}$ for $15 \mathrm{~min}$ at $4{ }^{\circ} \mathrm{C}$ to remove debris. Protein concentrations of supernatants were measured by Bradford assay (Axonlab).

\section{Measure of total IgG antibodies concentration by ELISA}

The concentration of IgGs, in culture media $(n=20)$ collected at day 0 and day 3 , and in protein extracts $(n=10)$ from degenerated IVDs, was quantified using a standard indirect ELISA procedure. Briefly, a 96-well plate (Nunc MaxiSorp, Fluka Chemie GmbH, Buchs, Switzerland) was coated with $50 \mu \mathrm{L} /$ well of $1 \mathrm{ng} / \mu \mathrm{L}$ Protein A (LuBioScience GmbH, Lucerne, Switzerland) in PBS. After incubation overnight at $4{ }^{\circ} \mathrm{C}$, wells were washed with PBS by plate washer (Beckman-Coulter, Nyon, Switzerland), and non-specific binding sites were blocked for 3-4 h with $100 \mu \mathrm{L} /$ well of blocking solution containing $5 \%$ TopBlock (LuBioScience) and $1.5 \mathrm{mg} /$ $\mathrm{mL}$ casein (Axonlab) in Tris-buffered saline (TBS). The coated plate was incubated overnight at $4{ }^{\circ} \mathrm{C}$ with $50 \mu \mathrm{L} /$
Table 2. Human marker genes used in quantitative RT-PCR.

\begin{tabular}{|c|c|c|}
\hline Gene & Primer nucleotide sequence (5'-3') & $\begin{array}{c}\text { Product } \\
\text { size (bp) }\end{array}$ \\
\hline GAPDH & $\begin{array}{c}\text { F-TGGACTCCACGACGTACTCA } \\
\text { R-GGAAGCTTGTCATCAATGGAA }\end{array}$ & 102 \\
\hline IL-17A & $\begin{array}{c}\text { F-TGGGAAGACCTCATTGGTGT } \\
\text { R-GGATTTCGTGGGATTGTGAT }\end{array}$ & 84 \\
\hline IL-6 & $\begin{array}{c}\text { F-AGCCAGAGCTGTGCAGATG } \\
\text { R-CTGCAGCCACTGGTTCTGT }\end{array}$ & 145 \\
\hline IL-8 & $\begin{array}{c}\text { F-AGACAGCAGAGCACACAAGC } \\
\text { R-AGGAAGGCTGCCAAGAGAG }\end{array}$ & 119 \\
\hline
\end{tabular}

$\mathrm{F}$, forward; $\mathrm{R}$, reverse.

well of disc medium diluted 1:100, 1:1000 and 1:5000, or $1 \mathrm{~h}$ at RT with $10 \mathrm{ng} / \mu \mathrm{L}$ of disc protein extract. Dilutions of purified human IgG (Bethyl - LuBioScience GmbH, Lucerne, Switzerland) were used for a standard curve. After washing with PBS, anti-human-IgG HRP-conjugated secondary antibody (A80-119P Bethyl), diluted 1:5000 in blocking mix $(50 \mu \mathrm{L} /$ well $)$, was added for $1 \mathrm{~h}$ at room temperature. Following washing with PBS, $100 \mu \mathrm{L}$ of o-phenylenediamine substrate (OPD, dissolved at $15.3 \mathrm{mg} /$ $\mathrm{mL}$ in citrate buffer, $\mathrm{pH}$ 5.0, Applichem - Axonlab, Baden, Switzerland) were added and left shortly to develop. The reaction was stopped with $10 \%$ sulphuric acid. Absorbance was measured at $450 \mathrm{~nm}$ by DTX 880 Multimode Detector (Beckman-Coulter) and concentration of IgGs $(\mathrm{ng} / \mathrm{mL})$ was determined from the standard curve.

\section{Detection of total and disc specific IgGs by immunohistochemistry analysis}

Bovine and human IVD fragments embedded in Tissue-Tek (Sakura) were sectioned at $10 \mu \mathrm{m}$ using a cryostat (Microm HM560, Histocom AG, Zug, Switzerland). Endogenous peroxidase was quenched by $3 \% \mathrm{H}_{2} \mathrm{O}_{2}$ in PBS at room temperature for $10 \mathrm{~min}$, and then washed with PBS. Before incubation with primary antibodies, sections were pretreated with $2500 \mathrm{U} / \mathrm{mL}$ hyaluronidase (Sigma) in PBS for $1 \mathrm{~h}$ at $37{ }^{\circ} \mathrm{C}$. Non-specific background was blocked with $10 \%$ normal goat serum (LubioScience) for $30 \mathrm{~min}$. To demonstrate the presence of IgG antibodies, human degenerated disc sections were incubated with anti-human HRP-conjugated secondary antibody diluted 1:1000 (A80$119 \mathrm{P}$, Bethyl) for $1 \mathrm{~h}$ at room temperature. Control healthy bovine disc sections were incubated with anti-bovine HRPconjugated secondary antibody diluted 1:1000 (A10-130P, Bethyl). As a positive control, anti-collagen type II Mab (II-II6B3, Development Studies Hybridoma Bank (DSHB), University of Iowa, Iowa City, IA, USA); diluted 1:40 in PBS) followed by anti-mouse HRP-conjugated secondary antibody diluted 1:1000 (A90-216P, Bethyl) was used.

To analyse the presence of IgGs against proteins of the disc, bovine healthy disc sections were incubated overnight at $4{ }^{\circ} \mathrm{C}$ with disc media collected after $3 \mathrm{~d}$ from human degenerated IVDs cultured in vitro. After washing with PBS, sections were incubated with anti-human HRPconjugated secondary antibody diluted 1:1000 (A80-119P, Bethyl) for $1 \mathrm{~h}$ at room temperature.

Sections were developed with TMB SP HRP substrate (SPPM-1000-01, BioFX - LuBioScience GmbH, Lucerne, 
Switzerland), mounted with VectaMount AQ (H-5501, Vector Lab. - Reactolab, Servion, Switzerland) and analysed by light microscopy (Olympus IX71, Olympus Schweiz AG, Volketswil, Switzerland).

\section{Detection of IgGs against disc ECM proteins by immunoblotting}

Purified ECM proteins: Human Collagen type I (288, Yo Proteins - LuBioScience GmbH, Lucerne, Switzerland), Human Collagen type II (30410424, ProteaImmun Anawa, Wangen, Switzerland), Human Collagen type III (889 Yo Proteins), Human Collagen type V (436 Yo Proteins), bovine aggrecan (A1960 Sigma) and proteins extracted from bovine healthy discs (oAF - iAF - NP) were diluted to $100 \mathrm{ng} / \mu \mathrm{L}$ in PBS. In dot blot assay $100 \mathrm{ng}$ $(1 \mu \mathrm{L})$ of each protein were spotted onto nitrocellulose membrane (Whatman - GE Healthcare, Glattbrugg, Switzerland) and dried for $1 \mathrm{~h}$ at room temperature. After blocking of non-specific sites with $5 \%$ fat-free milk (Rapilait, Migros, Switzerland) in PBS, the membrane was incubated with disc media collected after $3 \mathrm{~d}$ from human degenerated IVDs cultured in vitro $(1 \mu \mathrm{g}$ of total IgGs, as determined by ELISA) or monoclonal primary antibodies, diluted in $5 \%$ milk-PBS, overnight at $4{ }^{\circ} \mathrm{C}$. Monoclonal primary antibodies were used to control spotted proteins: monoclonal anti-Collagen type I (M38-s, DSHB; diluted 1:10); anti-Collagen type II (II-II6B3, DSHB; diluted 1:500); anti-Collagen type III clone MC3-HA (380, Yo Proteins; diluted 1:500); anti-aggrecan (AHP0022, Biosource - LuBioScience GmbH, Lucerne, Switzerland; diluted 1:500). After washing with PBS, the membrane was incubated $1 \mathrm{~h}$ at room temperature with anti-IgG secondary antibody conjugated with HRP (anti-mouse A90-216P; anti-human A80-119P Bethyl) diluted 1:5000 in 5\% milk-PBS, followed by washing with PBS and incubation with chemiluminescence substrate (EZ ECL, Biological Industries - LucernaChem, Lucerne, Switzerland). Acquisition was performed with a digital SLR camera (Nikon D600, Nikon, Zürich, Switzerland) (Khoury et al., 2010). Dot blots of 10 patients with degeneration of IVD were analysed and quantified by Image J version $1.46 \mathrm{r}$ for Windows (ImageJ Inc.) measuring the integrated density of each dot.

In Western blot assays, proteins were separated by SDS-PAGE using Tris-Glycine 5-15\% gels (BioRad) with a Protein Standard 10-250 kD (Precision Plus Protein Standard, BioRad) and transferred onto a nitrocellulose membrane using the semi-dry Trans-Blot Turbo system (BioRad). After blocking of non-specific sites with $5 \%$ milk (Rapilait) in PBS, the membrane was incubated for $4 \mathrm{~h}$ at room temperature with disc media collected after $3 \mathrm{~d}$ from human degenerated IVDs cultured in vitro $(1.75 \mu \mathrm{g}$ of total IgGs, as determined by ELISA) diluted in $5 \%$ milk-PBS. After washing with PBS, the membrane was incubated 90 min at room temperature with anti-human IgG secondary antibody conjugated with HRP (A80-119P Bethyl) diluted 1:10000 in 5\% milk-PBS, and after 3 washes with PBS, incubated with chemiluminescence substrate (LumiGlo Reserve KPL - Bio Concept,
Allschwil, Switzerland). Acquisition and analyses were performed as described above.

Isolation and culture of human and bovine disc cells Human IVD fragments (AF and NP separately) obtained from patients undergoing surgical intervention, were digested with $0.05 \%$ collagenase (Worthington - Bio Concept, Allschwil, Switzerland), $5 \%$ FBS, penicillin (100 units/mL) /streptomycin $(100 \mu \mathrm{g} / \mathrm{mL})$ in DMEM/ $\mathrm{F} 12+$ GlutaMAX (all Gibco) for $6 \mathrm{~h}$ at $37^{\circ} \mathrm{C}$. Healthy bovine disc fragments, obtained from tails of adult animals, were dissected and digested (1) with $0.3 \%$ pronase (Sigma-Aldrich), $5 \%$ foetal bovine serum (FBS), penicillin $(100$ units $/ \mathrm{mL}) /$ streptomycin $(100 \mu \mathrm{g} / \mathrm{mL})$ in DMEM/F12 + GlutaMAX for $1 \mathrm{~h}$ at $37{ }^{\circ} \mathrm{C}$; (2) with $0.05 \%$ collagenase (Worthington), $5 \%$ FBS, penicillin (100 units $/ \mathrm{mL}) /$ streptomycin $(100 \mu \mathrm{g} / \mathrm{mL})$ in DMEM/ F12 + GlutaMAX, overnight at $37{ }^{\circ} \mathrm{C}$. Disc cells were expanded in monolayer culture for $15 \mathrm{~d}$ in DMEM/F12 + GlutaMAX, supplemented with $10 \%$ FBS, penicillin (100 units $/ \mathrm{mL}$ ) / streptomycin $(100 \mu \mathrm{g} / \mathrm{mL}), 2.5 \mu \mathrm{g} / \mathrm{mL}$ Amphotericin B (Sigma) and $5 \mathrm{ng} / \mathrm{mL}$ recombinant bFGF (Peprotech - LuBioScience GmbH, Lucerne, Switzerland) at $37{ }^{\circ} \mathrm{C}$ in a humid atmosphere containing $5 \% \mathrm{CO}_{2}$.

At passage 1, cells were then grown in three dimensional cubes with $3 \mathrm{~mm}$ side length, made of gelatine, a partially hydrolysed collagen (Spongostan, Ferrosan AS, Soeborg, Denmark). Cell suspension was carefully pipetted on the construct $(72,000$ cells for cube, at density of 4,000,000 cells/mL) allowing cells to be completely absorbed. Constructs were kept at RT in a 6-well plate for $30 \mathrm{~min}$ to allow cells to anchor to the matrix, before adding media. To induce chondrogenesis, disc cell constructs were cultured for up to 5 weeks in chondrogenic medium: DMEM/ F12 + GlutaMAX supplemented with $2.5 \%$ FBS, $40 \mathrm{ng} /$ $\mathrm{mL}$ dexamethasone (Applichem), $50 \mu \mathrm{g} / \mathrm{mL}$ ascorbate2-phosphate (Sigma), $50 \mu \mathrm{g} / \mathrm{mL}$ L-proline (Sigma), $100 \mathrm{U} / \mathrm{mL}$ penicillin $/ 100 \mu \mathrm{g} / \mathrm{mL}$ streptomycin, $2.5 \mu \mathrm{g} / \mathrm{mL}$ amphotericin B, 1X insulin $(10 \mu \mathrm{g} / \mathrm{mL})$, transferrin $(5.5 \mu \mathrm{g} /$ $\mathrm{mL})$, selenium $(0.67 \mathrm{ng} / \mathrm{mL})$, X supplement (ITS, Gibco), and $10 \mathrm{ng} / \mathrm{mL}$ transforming growth factor- $\beta 1$ (TGF- $\beta 1$ ) (Peprotech). Controls were maintained in control medium without TGF- $\beta 1$.

To extract proteins, frozen constructs were hammer and lysed with $300 \mu \mathrm{L}$ of CelLytic M Cell Lysis Reagent (Sigma). To prevent degradation, Protease Inhibitor Cocktail (Sigma) was added. Extracted disc cell proteins were used to perform Western blot assay with disc media collected after $3 \mathrm{~d}$ from human degenerated IVDs fragments cultures in vitro.

\section{Statistical analysis}

For statistical analysis we used the non-parametric MannWhitney-Wilcoxon $U$ test for dependent variables. Data were expressed as the mean $\pm \mathrm{SD}$. Values of $p$ were labelled as significant when $p<0.05$ (a); $p<0.01$ (b); $p<0.001$ (c). Data analysis was performed with SPSS version 14.0 for Windows (SPSS Inc.). 
Fig. 1. Human degenerated IVDs contain IgG antibodies. (a) The concentration of IgGs in disc media collected at day 0 and day 3 , from human degenerated IVDs cultured in vitro, was measured by ELISA assay $(n=20)$. The total amount of IgGs normalised to disc fragment weight was significantly lower in culture media collected after $3 \mathrm{~d}$ from thoroughly washed disc fragments, compared to media from day 0 collected shortly after surgery (AF $p<0.05$; NP $p<0.01$ ). (b) The presence of IgGs was detected by dot blot in total protein extracts from healthy bovine (left) and degenerated human (right) discs. The spots represent: purified IgG (used as positive controls), AF protein extracts and NP protein extracts. Anti-human-IgG antibody shows strong signal in human degenerated AF and NP extracts (dark staining, right), while antibovine-IgG antibody shows no signal (absence of staining, left) in healthy bovine disc protein extracts. (c) The amount of total IgGs in human degenerated AF and NP protein extracts $(n=10)$ measured by ELISA assay. The concentration of IgGs was normalised to grams of total proteins. (Values are displayed as mean $\pm \mathrm{SD}$. Black columns represent $\mathrm{AF}$, white columns NP. Values of $p$ are labelled as $\mathrm{a}=$ $p<0.05 ; \mathrm{b}=p<0.01$ ).

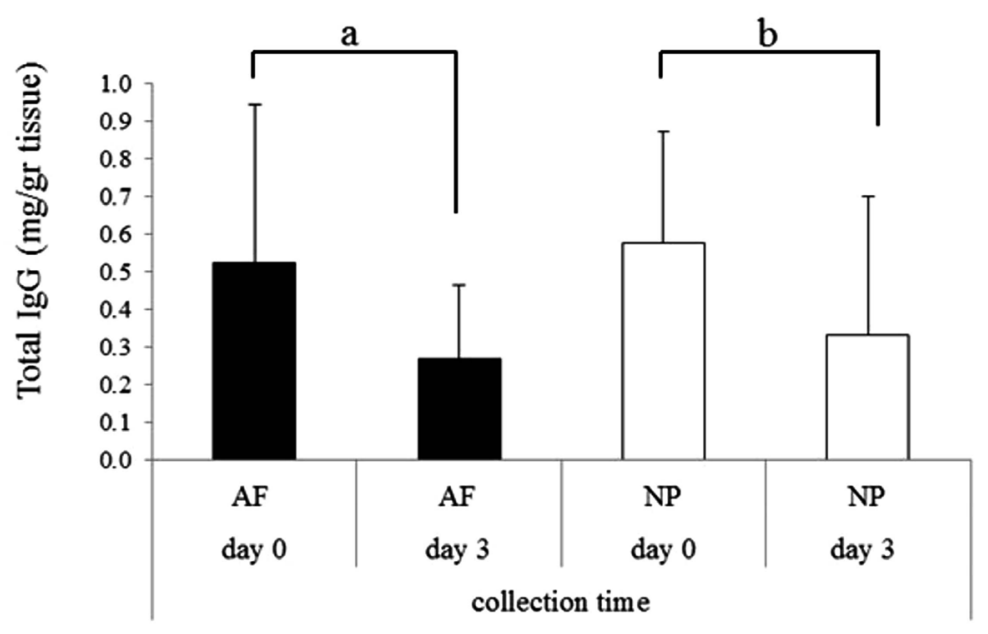

b

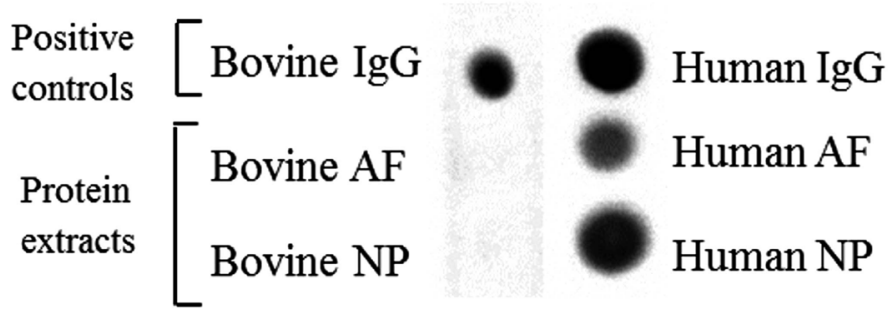

C Total IgG in protein extracts of human degenerated IVDs

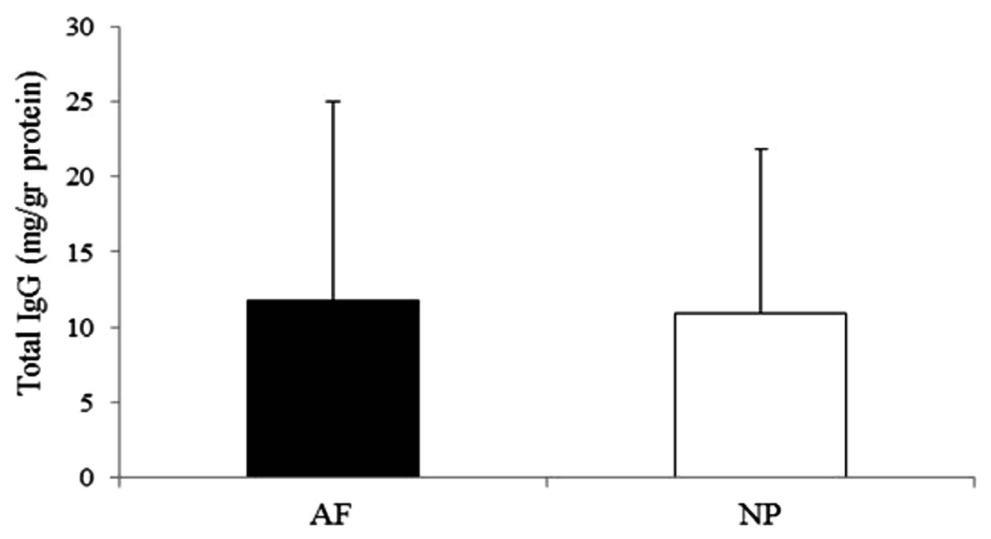

\section{Results}

Human degenerated IVDs contain IgG antibodies Degenerated and post-traumatic human AF and NP fragments, obtained from patients undergoing discectomy (Table 1), were washed to remove blood residues from operative field and cultured in vitro for a period of three days. We collected disc media in contact with disc fragments shortly after surgery (disc medium day 0 ), and after $3 \mathrm{~d}$ of thoroughly washed disc fragment in vitro cultures (disc medium day 3). Using ELISA, we demonstrated that $\operatorname{IgG}$ antibodies were still present in washed degenerated discs fragments and measured that the concentration of IgGs in disc culture media collected after $3 \mathrm{~d}$, was significantly lower (AF $p<0.05$; NP $p<0.01$ ) compared to media collected at day 0 (Fig. 1a). There were no differences between AF and NP fragments at the same collection time. As a healthy control, we cultured in vitro bovine caudal discs, but we could not detect bovine antibodies in disc media (data not shown). By dot blot assay, we demonstrated the presence of IgGs in total protein extracts of human degenerated IVD fragments, further washed after $3 \mathrm{~d}$ of culture in vitro. Immunoblot revealed robust signal in human degenerated protein extracts incubated with anti-human IgG antibody, while no signal was detected in healthy bovine controls after incubation with anti-bovine-IgG antibody. Purified human and bovine IgGs were used as positive controls (Fig. 1b). The concentration of IgGs in total protein extracts from human degenerated IVDs was determined by ELISA 
DDD grade III $\quad$ DDD grade IV

$\begin{array}{lll}\text { hAF hNP } & \text { hAF }\end{array}$

2. Human degenerated IVDs express molecular mediators of inflammation. Representative image of agarose electrophoresis shows gene expression of interleukins 17A (IL-17A), 6 (IL-6), 8 (IL-8) and GAPDH (house-keeping gene), by RT-PCR, in human degenerated discs ( $\mathrm{hAF}$ and $\mathrm{hNP}$ ) with degeneration grade III and IV.
IL-17A

IL-6

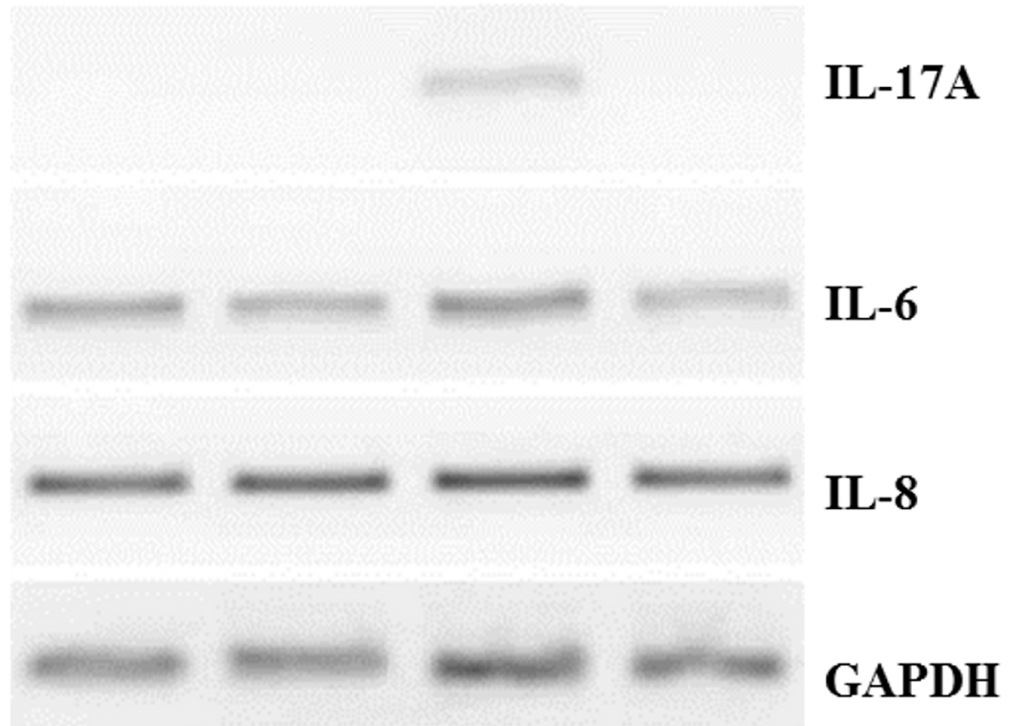

assay (Fig. 1c). No significant differences between protein extracts from $\mathrm{AF}$ and NP fragments and no correlation with degeneration grade could be observed.

\section{Human degenerated IVDs express molecular mediators of inflammation}

Gene expression analysis of human degenerated IVDs revealed the presence of molecular mediators of inflammation mRNAs. Interleukin-6 (IL-6) and Interleukin-8 (IL-8) were present in all tissue samples and there were no differences between AF and NP or degeneration grade. Interleukin 17A (IL-17A) was present at very low levels and only in AF samples with high degeneration grade (Fig. 2).

\section{Detection of IgGs in human degenerated IVDs}

Immunohistochemistry (IHC) analysis showed the presence of $\mathrm{IgG}$ antibodies in human degenerated IVD sections (Thompson grade III). AF and NP tissues displayed a strong signal when incubated with anti-human-IgG antibody, while the negative control anti-bovine- $\operatorname{IgG}$ antibody showed no signal (Fig. 3a). The absence of infiltrated IgGs in healthy disc samples was demonstrated by lack of signal in IHC analysis of healthy bovine AF and NP sections incubated with anti-bovine and anti-human-IgG antibodies (Fig. 3b). In both human and bovine discs, IHC staining with monoclonal anti-Collagen type II antibody was used as positive control.

Culture media of human degenerated IVDs contain IgG antibodies against proteins of healthy disc We detected the release of IgGs into in vitro culture media, collected at day 3 from human degenerated IVDs (Thompson grade III), by using these media as primary antibodies against healthy bovine AF and NP sections (Fig. 4a). The IHC analysis showed disc specific IgGs (dark blue staining), mainly against NP sections $(p<0.05)$ (Fig. 4b). Similar trends were observed in disc media collected at day 0 (data not shown). As shown in the previous paragraph, we could not use human disc sections in IHC analysis for the presence of antibodies inside (see Fig. 3a). Therefore we used healthy bovine discs, which did not give signal when incubated with anti-human IgG secondary antibody (see Fig. 3b).

\section{IgGs present in human degenerated IVDs target native ECM proteins}

To identify if antibodies found in human degenerated IVDs, recognise proteins of the disc, we spotted on nitrocellulose membranes, proteins extracts from healthy bovine discs (bovine AF outer, AF inner and NP), along with purified proteins of extracellular matrix (ECM), such as human Collagens type I, type II, type III, type V and bovine aggrecan. We detected IgGs against bovine disc protein extracts in human disc media collected after $3 \mathrm{~d}$ from $\mathrm{AF}$ and NP cultured in vitro, and we also found specific IgGs against ECM purified proteins (Fig. 5a). None of the samples showed IgGs against purified human Collagen type III. Anti-human IgG antibody, used as negative control, did not non-specifically stain any of the proteins, whereas monoclonal primary antibodies against Collagen type I, type II, type III and aggrecan, used as positive controls, showed reactivity with their respective proteins. The quantitative analysis of dot blots (Fig. 5b) revealed more IgGs against NP extracts compared to AF $(p<0.01)$. In particular, more anti-collagen type II $(p<0.01)$ and anti-aggrecan ( $p<0.05$ for NP culture disc media) IgGs were detected, compared to anti-collagen type I antibodies. The analysis also showed a strong amount of antibodies against Collagen type V. 
a Degenerated human disc sections:

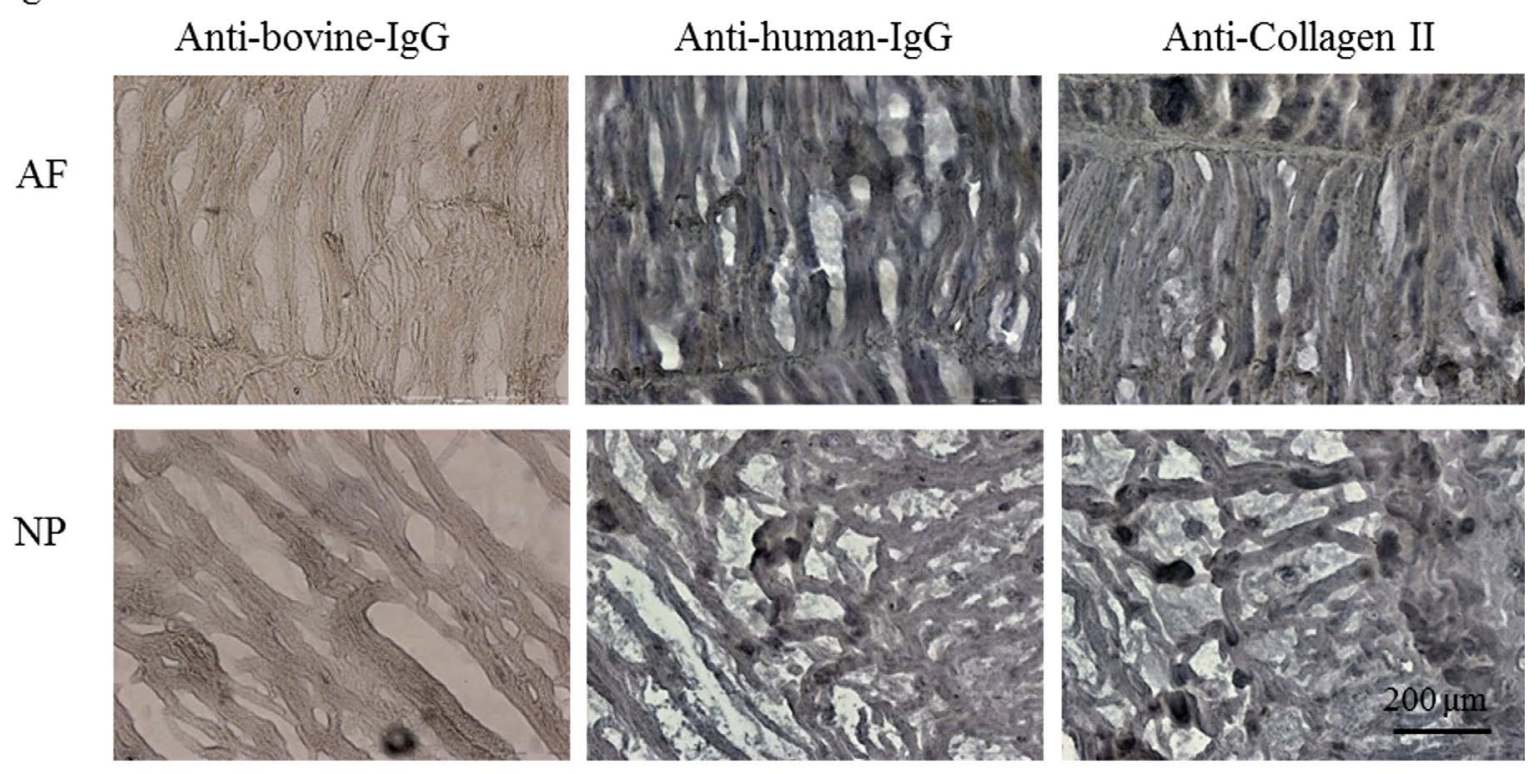

b Healthy bovine disc sections:

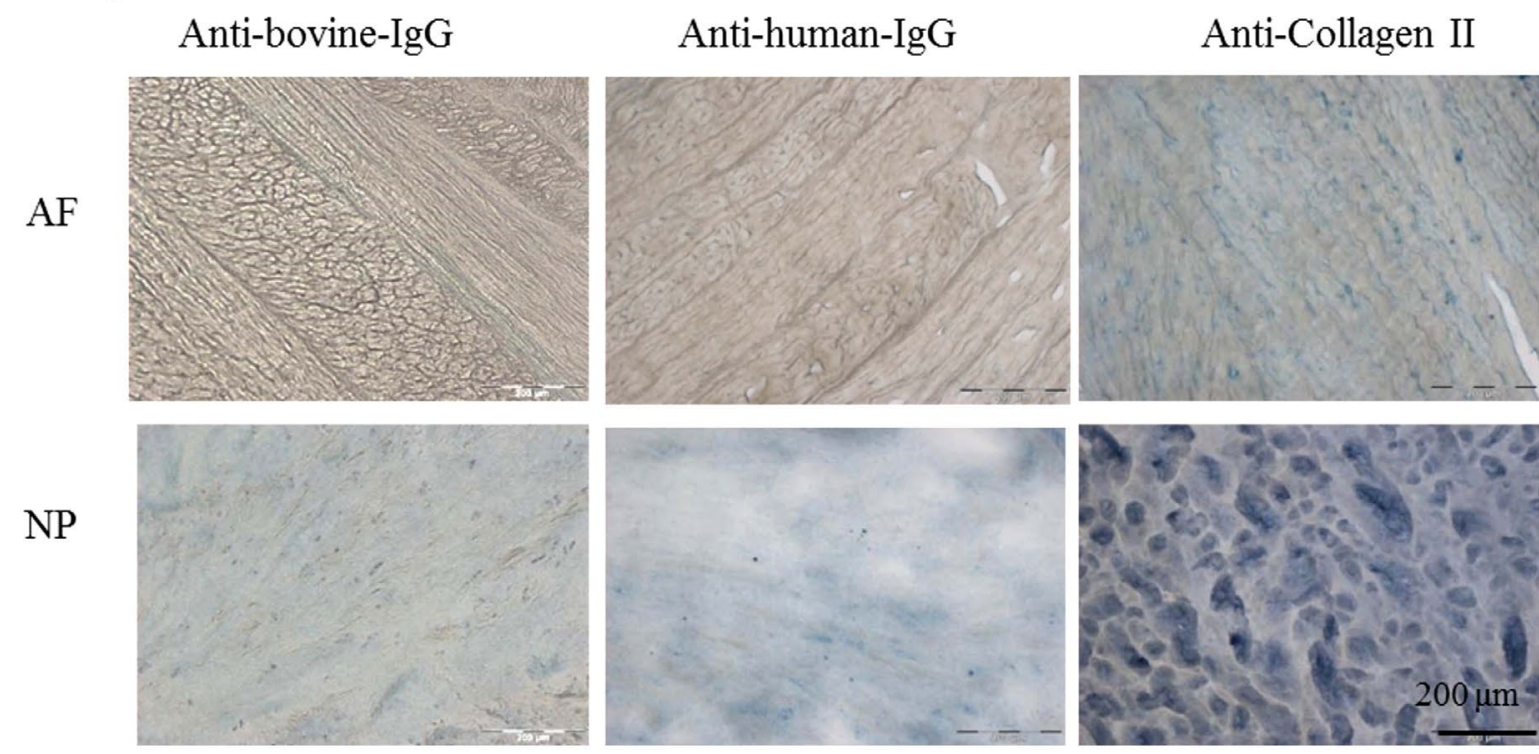

Fig. 3. Detection of IgGs in human degenerated IVDs. (a) Immunohistochemistry shows the presence of human IgGs (dark blue staining) in degenerated IVD sections (AF and NP). In negative controls human disc tissues were incubated with anti-bovine-IgG antibody. (b) No IgGs were detected in healthy bovine disc sections incubated with anti-human and anti-bovine-IgG antibodies. Anti-Collagen II monoclonal antibody was used as a positive control for both human and bovine disc sections (Scale bar $=200 \mu \mathrm{m})$.

\section{Western blot detection of ECM proteins by IgGs released from human degenerated IVDs}

Western blot of healthy bovine disc proteins (bAF and bNP) and purified ECM proteins (human Collagen type I, type II, type V and bovine aggrecan) separated by SDS PAGE, was probed with disc media, collected at day 3 from human degenerated IVDs cultures (Fig. 6a). The assay revealed a major band with a molecular mass about of $130 \mathrm{kDa}$, matching the monomeric form of collagen. The higher bands in Collagen type I and type II lanes correspond to molecular weights of dimeric $(\sim 270 \mathrm{kDa})$ and trimeric $(\sim 400 \mathrm{kDa})$ collagen forms. The assay also showed a weak signal against a degradation product of aggrecan $(\sim 130 \mathrm{kDa})$. Quantification of densitometry (Fig. $6 b$ ) revealed that signal generated by equal amounts of denatured proteins, was significantly stronger against collagen type II, compared to collagen type I $(p<0.05$ in NP culture media; not significant in AF culture media). Furthermore, more reactivity was measured against healthy bovine NP compared to AF protein extract $(p<0.05$ in AF culture media; not significant in NP culture media). 
a

Culture media of human degenerated IVDs

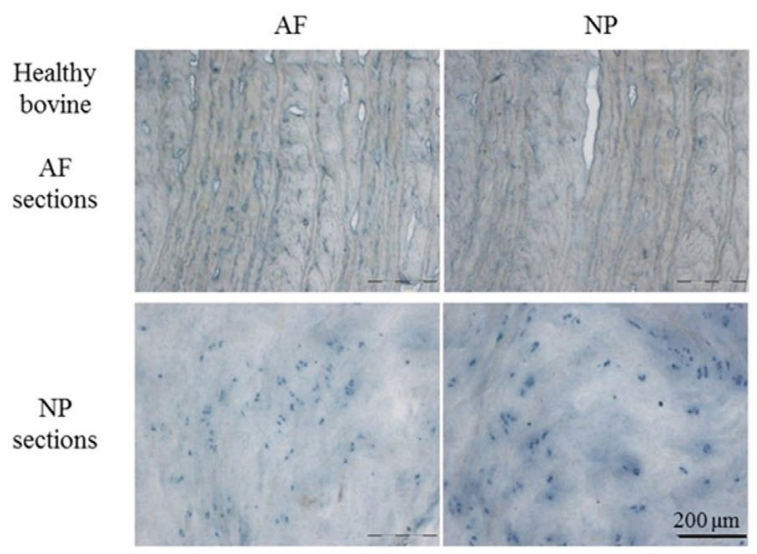

b

Culture media of human degenerated IVDs

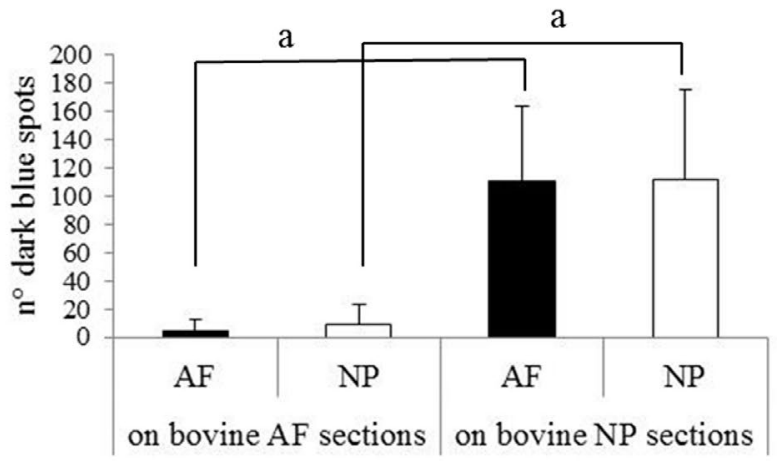

Fig. 4. Culture media of human degenerated IVDs contain $\operatorname{IgG}$ antibodies against proteins of healthy disc. (a) Immunohistochemistry on bovine healthy disc sections (AF and NP) shows the presence of disc specific antibodies (dark blue staining) in media collected at day 3 from human degenerated IVD cultured in vitro (Thompson grade III) (Scale bar $=200 \mu \mathrm{m})$. (b) The quantification of dark blue staining revealed disc specific IgGs mainly against NP $(p<0.05)$. (Values are displayed as mean \pm SD. Black columns represent AF, white columns NP. Values of $p$ are labelled as a $=p<0.05)$.

Fig. 5. IgGs present in human degenerated IVDs target native ECM proteins. (a) Dot blot on healthy bovine disc protein extracts (bovine AF outer, AF inner and NP) and purified ECM proteins (human Collagen type I, type II, type III, type $\mathrm{V}$ and bovine aggrecan) shows the presence of specific IgGs for all detected proteins except Collagen type III, in culture media collected at day 3 from human degenerated IVDs. Monoclonal primary antibodies (anti-Collagen type I, type II, type III and anti-aggrecan) were used as positive controls, while antihuman-IgG antibody was used as a negative control. Rows represent spotted proteins, while columns represent monoclonal antibodies and disc culture media used as primary antibodies. (b) Culture media collected from human degenerated IVDs $(n=10)$ showed more IgGs against NP than $\mathrm{AF}$ bovine protein extracts $(p<0.01)$; in particular more $\operatorname{IgGs}$ against collagen type II $(p<0.01)$ and aggrecan $(p<0.05$ for NP culture media) compared to collagen type I. (Dot blot quantification by Image J software - black columns represent IgGs in AF, white columns in NP culture media; values are displayed as mean $\pm \mathrm{SD}$. Values of $p$ are labelled as $\mathrm{a}=p<0.05 ; \mathrm{b}=p<0.01$ ). a
Monoclonal primary antibody
Culture media of human degenerated IVDs

\begin{tabular}{|c|c|c|c|c|c|c|}
\hline 0 & & ? & & bAF outer & & s \\
\hline - & 6 & 0 & & bAF inner & & e \\
\hline c & $\mathrm{C}$ & & & bNP & & 8 \\
\hline 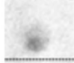 & c & C & & hCollagen I & & $x$ \\
\hline 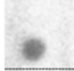 & $\mathrm{C}$ & & & hCollagen II & & 6 \\
\hline & & $\bullet$ & & hCollagen III & & \\
\hline & B & , & & hCollagen V & & $\bullet$ \\
\hline & & & & bAggrecan & & 32 \\
\hline 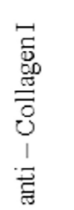 & 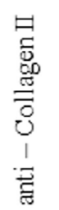 & 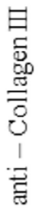 & 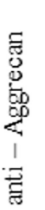 & & 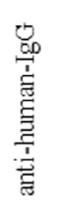 & $\mathrm{AF}$ \\
\hline
\end{tabular}

b

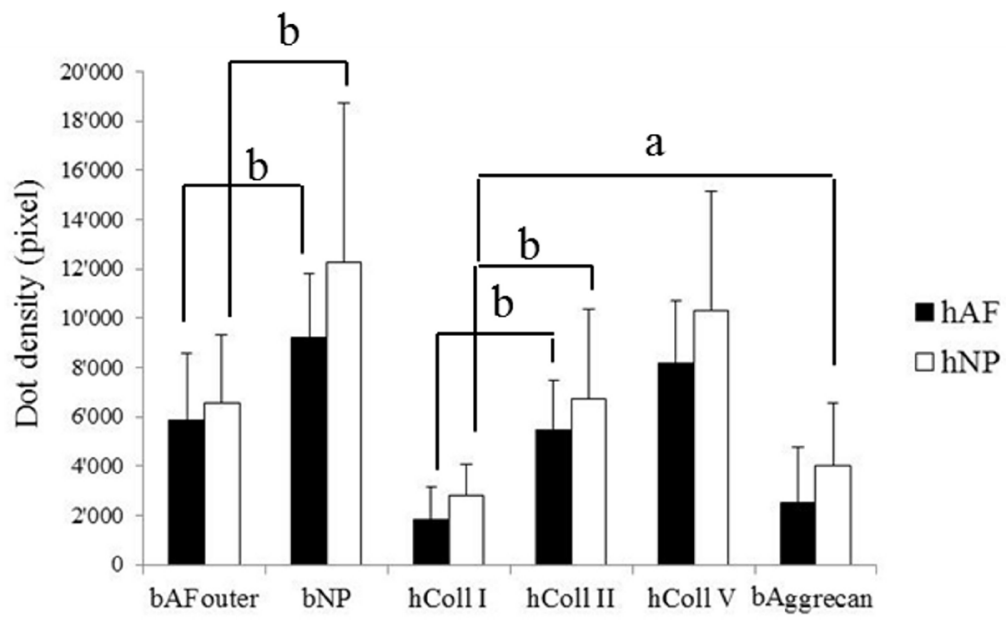


a

Fig. 6. Western blot detection of ECM proteins by IgGs released from human degenerated IVDs. (a) Bovine disc protein extracts (AF and NP) and purified ECM proteins (human Collagen type I, type II, type $\mathrm{V}$ and bovine aggrecan) were analysed by Western blot. Disc media collected after $3 \mathrm{~d}$ from human degenerated IVDs cultured in vitro were probed for binding of IgGs to proteins separated by SDS-PAGE. Blot shows the presence of IgGs against disc protein extracts and in particular against the monomeric form of collagen $(130 \mathrm{kDa})$ and a degradation product of aggrecan. (b) Immunoblot quantification by Image $J$ software shows that signal generated on equal amount of protein, by human degenerated IVD culture media $(n=8)$, is stronger against denatured collagen type II compared to collagen type I $(p<0.05$ in NP culture media). As well, signal against denatured NP proteins is slightly higher compared to AF protein extracts $(p<0.05$ for AF culture disc media). (Black columns represent AF, white columns NP; values are displayed as mean $\pm \mathrm{SD}$. Values of $p$ are labelled as $\mathrm{a}=$ $p<0.05)$.

$b$

\section{Culture medium of human degenerated $\mathrm{AF}$}

\section{bAF bNP hCI hCII hCV bAggrecan}

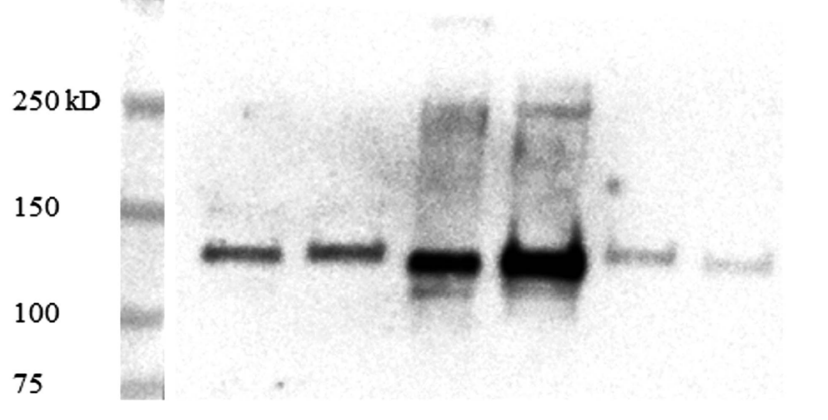

Culture medium of human degenerated NP
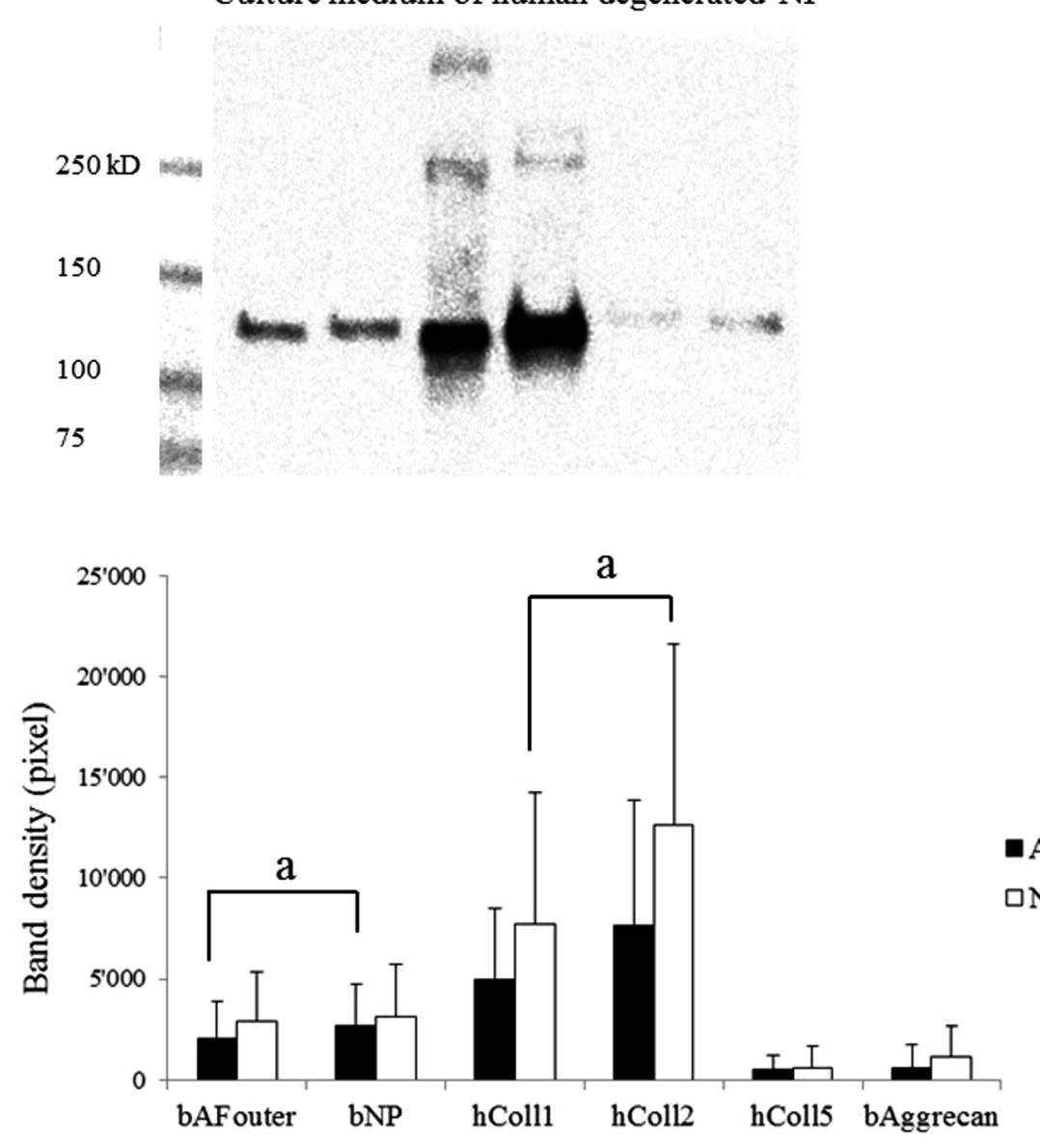

IgGs present in human degenerated IVDs recognise disc cell proteins

We stimulated cells extracted from human degenerated AF and NP fragments to produce specific disc proteins, in chondrogenic and non-chondrogenic (control) threedimensional (3D) cultures. The chondrogenic differentiation was confirmed by gene expression of specific markers by RT-PCR analysis (data not shown). Protein extracts from stimulated human and bovine disc cells and respective controls were probed with culture media collected after $3 \mathrm{~d}$ from human degenerated discs. Western blot analysis revealed characteristic bands with molecular weights between 100 and $150 \mathrm{kDa}$, in human degenerated NP culture medium (Fig. 7, top). Disc medium from human degenerated AF gave similar but weaker signal, detectable only against bovine stimulated disc cells (Fig. 7, bottom).

\section{Discussion}

In this study we confirmed the presence of $\operatorname{IgG}$ antibodies, as a sign of lymphocyte infiltration, in degenerated and post-traumatic IVDs, and we found that these antibodies are directed against typical extracellular proteins of the disc, mostly against proteins of the NP.

We quantified IgGs released by disc fragments in media collected shortly after surgery (disc medium day 0 ), and after $3 \mathrm{~d}$ from thoroughly washed disc fragments cultured 


\section{Culture medium of human degenerated NP}

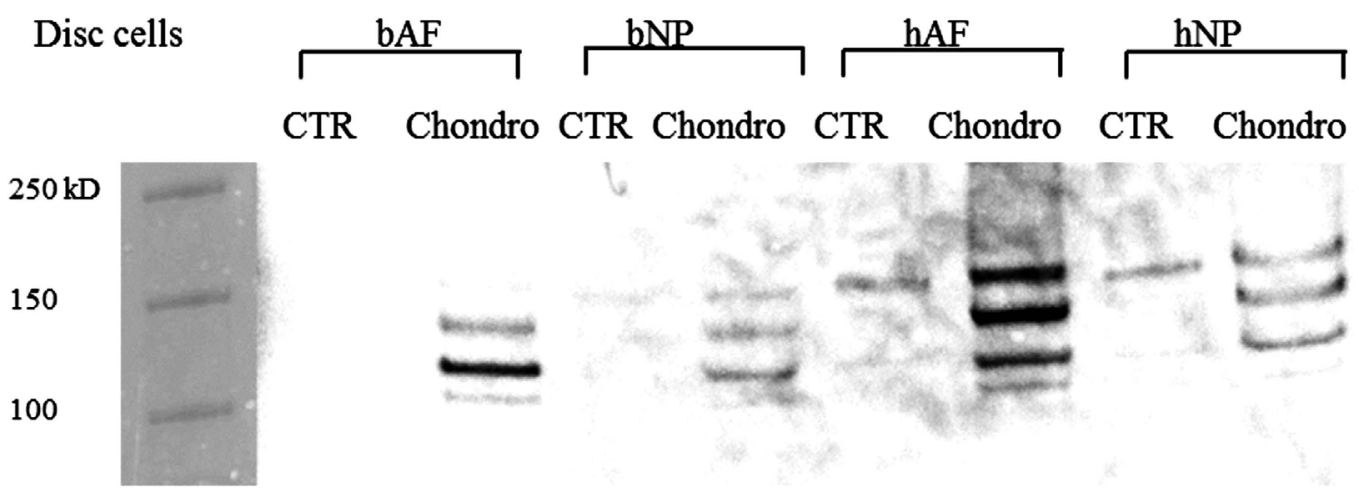

\section{Culture medium of human degenerated $\mathrm{AF}$}

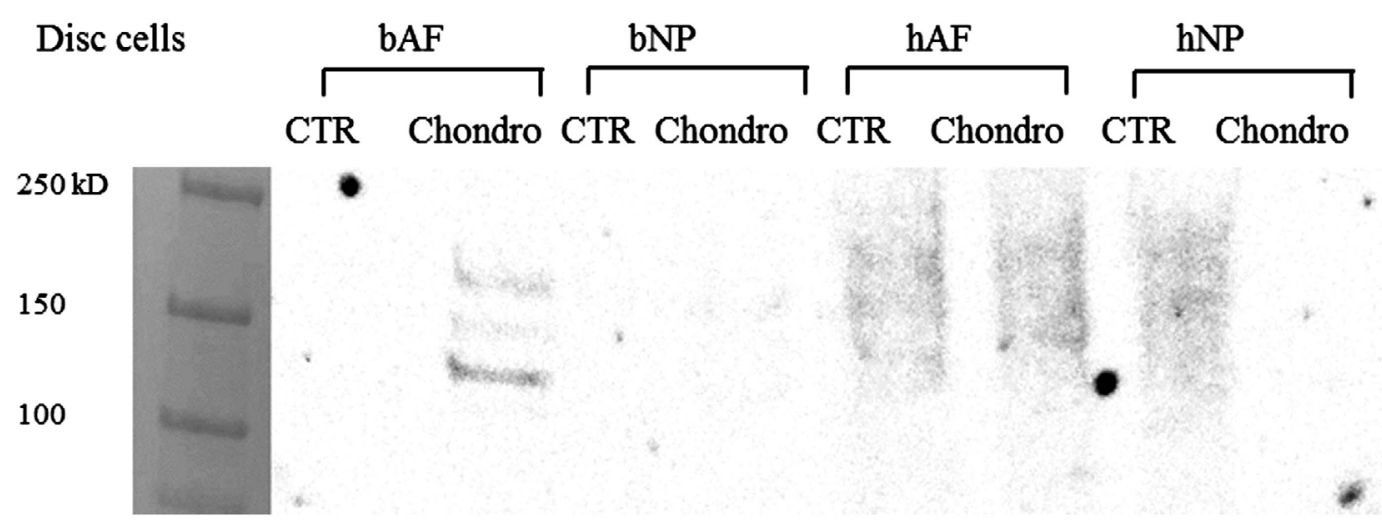

Fig. 7. IgGs present in human degenerated IVDs recognise disc cell proteins. Proteins extracted from bovine and human disc cells, cultured in a three-dimensional (3D) scaffold and stimulated to produce proteins specific of disc (chondrogenic differentiation), were separated by SDS-PAGE. Controls (CTR) correspond to non-stimulated disc cells. Western blot with disc medium collected after $3 \mathrm{~d}$ from human degenerated NP cultured in vitro, reveals bands with molecular weight between 100 and $150 \mathrm{kDa}$, against both human and bovine stimulated disc cells (top). Disc medium from human degenerated AF gives similar but weaker signal, detectable only against bovine stimulated disc cells (bottom).

in vitro (disc medium day 3 ). We demonstrated that specific $\mathrm{IgG}$ antibodies were still present in media collected from washed degenerated disc fragments, but in significantly less amounts compared to media collected at day 0 , which could contain additional non-specific antibodies from surgery blood residues. To confirm that antibodies found in disc culture media are released by the degenerated disc, and not from operative bleeding, we measured the concentration of IgGs in protein extracts from further washed degenerated AF and NP fragments. The average of IgGs concentration appeared similar between AF and NP extracts, probably because advanced degeneration and surgical routine make it difficult to separate well the AF from the NP in a degenerated disc. However, if disc tissues were not severely degenerated and thus easily separated by the surgeon, we found a higher concentration of antibodies in the NP compared to the AF protein extracts. As no healthy human samples were obtainable, we used healthy bovine caudal discs as controls and demonstrated that protein extracts from healthy discs contain no antibodies.
Additionally, no antibodies were found in healthy bovine disc tissue sections probed with anti-bovine IgG antibody.

We also found the presence of some molecular mediators of inflammation, such as IL-6, IL-8 and traces of IL-17, in analysed degenerated samples. Previous studies reveal the presence of cytokines (Le Maitre et al., 2007) and inflammatory mediators (Burke et al., 2002) in herniated and degenerated discs, and suggest the involvement of lymphocytes in disc degeneration (Shamji et al., 2010). Inflammation and back pain are correlated with increasing innervation and vascularisation of the disc (Stefanakis et al., 2012) and it is hypothesised that $\mathrm{NP}$, in contact with the systemic circulation, can trigger lymphocyte activation and an autoimmune response (Habtemariam et al., 1996). Undefined antigen-antibody complexes have been found in herniated disc tissues (Satoh et al., 1999), but the authors did not show that the antigens are collagens or proteoglycans.

In an earlier study we have detected IgG antibodies in human degenerated and post-traumatic disc fragments 
cultured in vitro (Bertolo et al., 2011), but we did not identify their targets. Based on the above mentioned data and studies, we put to test the hypothesis that if the integrity of vertebral endplates is compromised by trauma or degeneration, antibodies against disc proteins would be present locally. After confirming the presence of human IgGs, we showed that they correlated to the amount of collagen II in degenerated AF and NP sections, further supporting the autoimmune hypothesis. To investigate if the antibodies found in degenerated IVDs are produced against proteins of the disc, we used healthy - antibody free - bovine AF and NP disc sections as targets in immunohistochemistry assays. Human IgGs from degenerated IVDs probed strongly NP specific proteins in bovine disc sections. Immunoblot assays confirmed independently this strong autoimmune response against NP proteins and to lower extent against AF proteins. To test the specificity of the immune response, we used highly purified extracellular matrix proteins as antigens. Greater amounts of antibodies against a major constituent of the NP - collagen type II - were extracted from human IVDs, compared to IgGs against the major constituent of AF - collagen type I. Animal model studies also have demonstrated that autologous NP can induce inflammation and an autoantibody response in rabbits (Bobechko and Hirsch, 1965), dogs (McCarron et al., 1987), pigs (Geiss et al., 2007) and rats (Murai et al., 2010).

Different antibodies can bind different epitopes of the same protein, or even distinguish between native and denatured proteins. We separated purified human proteins and bovine disc extracts by SDS-PAGE and performed a Western blot using culture media of human degenerated discs as the primary polyclonal antibody probe. The assay confirmed the presence of IgGs principally against the monomeric form of collagen type II and similar, but weaker signal, against collagen type I. Involvement of collagen type II in the autoimmune reaction is highly probable; IVD degeneration has been correlated with increased degradation of collagen II (Antoniou et al., 1996), yet collagen II might trigger articular cartilage diseases (Burkhardt et al., 2002) and antibodies to denatured collagens have been found in patients with rheumatoid arthritis (RA) (Morgan et al., 1987). We also found antibodies against the minor fibrillar human collagen type $\mathrm{V}$, which plays a role in the organisation of heterotypic type I/V collagen fibrils (Birk, 2001). Interestingly strong signal against native collagen type $\mathrm{V}$ was observed only with dot blot assay, but not with SDS electrophoresis and Western blot, probably because under denaturing conditions collagen $\mathrm{V}$ epitopes are no longer properly recognised by specific antibodies. Identifying antibodies against all these proteins raises the question if autoimmune reactivity in the disc is not generic to the whole collagen family? Probably not, as we could not find IgGs against collagen type III, a collagen present in outer AF of degenerated IVDs and correlated with altered metabolism of disc tissue (Adam and Deyl, 1984).

Additionally, we investigated if the dominant component of the NP - the proteoglycan aggrecan - can also be a target of autoimmune response in the process of IVD degeneration. Indeed, with dot blot assay, we detected antibodies against purified bovine aggrecan in culture media of human degenerated discs. However, upon further analysis of IgGs against denatured protein by western blot, we observed a low intensity band, which does not correspond to the molecular weight of the native aggrecan core protein $(210-250 \mathrm{kDa})$, but to a degradation product of the protein (approx. $130 \mathrm{kDa}$ ). This observation makes biological sense, as cleavage events at metalloproteinase and aggrecanase sites are normal in aggrecan catabolism (Sztrolovics et al., 1997). Slow release of aggrecan degradation products into the blood seems to be related to progression of IVD degeneration (Roughley et al., 2006). Furthermore, an approx. $140 \mathrm{kDa}$ aggrecan degradation product generated by calpain cleavage, and correlating with the stage of degeneration, has been found in degenerated disc tissue (Fukuta et al., 2011).

Proteins in the extracellular matrix often have quaternary structures and modification, and also are partially degraded, compared to proteins freshly synthesised from the cell. It was a fundamental question to understand if the autoimmune response is targeting the extracellular matrix alone or also cells which synthesise fresh proteins. Indeed, we demonstrated that autoantibodies from degenerated IVDs recognise freshly synthesised disc cell proteins. To mimic the in vivo environment and induce chondrogenic differentiation (Bertolo et al., 2012), we grew cells from human degenerated discs and bovine healthy discs in 3D scaffolds, extracted their total protein content and observed that antibodies from human degenerated discs recognise proteins from the extracts.

Disc degeneration, as a multifactorial disease, correlates with different variables, such as genetic predisposition, altered metabolism, structural changes and neurovascular ingrowth (Adams and Roughley, 2006). In this study we looked at autoimmune response as an additional source of degenerative changes. Although it may seem to be secondary and to be triggered by an already present degeneration, these findings may have implications for diagnostics beyond self-reported back pain. Yet the diagnostic value of our findings is unclear, as patients suffering of degenerative disc disease (DDD) could also have osteoarthritis (OA), making it difficult to separate between these two conditions based only on the immunological profile. Nevertheless, epitope specificity could differ between diseases, as well as specific epitopes found to contribute to development of arthritis (Nandakumar et al., 2008), so hope remains that further studies will find unique epitopes, which will bring the needed diagnostic specificity and sensitivity.

Looking at the underlying biology of the process, we positively proved the association between autoimmunity and disc degeneration, previously shown as presence of autoantibodies in sera of patients with degenerated and herniated IVDs (Mihn and Kim, 2011). Autoantibodies present in degenerated discs may contribute to a vicious circle of "frustrated healing", where structural damage and consequential stress within the disc, lead to progressive degeneration (Adams and Dolan, 2012). Future discovery of epitopes specific for the immune response in the disc can lead to the development of diagnostic tests for disc degeneration in early stages and possibly to treatments, 
which can limit the autoimmune damage and initiate tissue repair. From a diagnostic perspective it is more interesting to detect circulating plasma antibodies in patients with degenerative disc disease. This might require using new, more sensitive methods - a previous study identified only 4 out of 60 sera of patients with back pain which reacted to proteins extracted from herniated NP (Kim et al., 1981). Early detection can change the way disc degeneration is treated - either by pharmaceutical interventions or by advanced cell therapies. Presumably, cell-based therapies applied in very early stages of disc degeneration (Paesold et al., 2007) may have better outcomes than when the degenerative changes are advanced.

\section{Conclusions}

We demonstrated that degenerated and post-traumatic IVDs can activate an autoimmune reaction, producing antibodies against specific proteins of the disc and more specifically the NP. Discrete antigens, mainly collagen type II and aggrecan degradation products are among the targets of an autoimmune response in the degenerated IVDs. We believe that our findings will draw new attention to the possible development of monitoring markers for prognosis, diagnosis and therapy related to disc degenerative diseases.

\section{Acknowledgments}

This work was supported by the Swiss Paraplegic Foundation and Swiss National Foundation (Grant CR32I3_140717/1 to JS). We thank Cherry Malonzo Marty for her help with manuscript correction. We wish to confirm that there are no known conflicts of interest associated with this publication and there has been no significant financial support for this work that could have influenced its outcome.

\section{References}

Adam M, Deyl Z (1984) Degenerated annulus fibrosus of the intervertebral disc contains collagen type II. Ann Rheum Dis 43: 258-263.

Adams MA (2004) Biomechanics of back pain. Acupunct Med 22: 178-188.

Adams MA, Dolan P (2012) Intervertebral disc degeneration: evidence for two distinct phenotypes. J Anat 221: 497-506.

Adams MA, Roughley PJ (2006) What is intervertebral disc degeneration, and what causes it? Spine 31: 21512161.

Antoniou J, Steffen T, Nelson F, Winterbottom N, Hollander AP, Poole RA, Aebi M, Alini M (1996) The human lumbar intervertebral disc: evidence for changes in the biosynthesis and denaturation of the extracellular matrix with growth, maturation, ageing, and degeneration. J Clin Invest 98: 996-1003.

Bertolo A, Thiede T, Aebli N, Baur M, Ferguson SJ, Stoyanov JV (2011) Human mesenchymal stem cell co- culture modulates the immunological properties of human intervertebral disc tissue fragments in vitro. Eur Spine J 20: $592-603$.

Bertolo A, Mehr M, Aebli N, Baur M, Ferguson SJ, Stoyanov JV (2012) Influence of different commercial scaffolds on the in vitro differentiation of human mesenchymal stem cells to nucleus pulposus-like cells. Eur Spine J 21 Suppl 6: S826-838.

Birk DE (2001) Type V collagen: heterotypic type I/V collagen interactions in the regulation of fibril assembly. Micron 32: 223-237.

Bobechko WP, Hirsch C (1965) Auto-immune response to nucleus pulposus in the rabbit. J Bone Joint Surg $\mathrm{Br} 47$ : 574-580.

Burke JG, Watson RW, McCormack D, Dowling FE, Walsh MG, Fitzpatrick JM (2002) Intervertebral discs which cause low back pain secrete high levels of proinflammatory mediators. J Bone Joint Surg Br 84: 196201.

Burkhardt H, Koller T, Engstrom A, Nandakumar KS, Turnay J, Kraetsch HG, Kalden JR, Holmdahl R (2002) Epitope-specific recognition of type II collagen by rheumatoid arthritis antibodies is shared with recognition by antibodies that are arthritogenic in collagen-induced arthritis in the mouse. Arthritis Rheum 46: 2339-2348.

Fukuta S, Miyamoto K, Suzuki K, Maehara H, Inoue T, Hara A, Kikuike K, Taguchi A, Shimizu K (2011) Abundance of calpain and aggrecan-cleavage products of calpain in degenerated human intervertebral discs. Osteoarthritis Cartilage 19: 1254-1262.

Geiss A, Larsson K, Rydevik B, Takahashi I, Olmarker K (2007) Autoimmune properties of nucleus pulposus: an experimental study in pigs. Spine 32: 168-173.

Habtemariam A, Gronblad M, Virri J, Seitsalo S, Ruuskanen M, Karaharju E (1996) Immunocytochemical localization of immunoglobulins in disc herniations. Spine 21: 1864-1869.

Johnson WE, Caterson B, Eisenstein SM, Hynds DL, Snow DM, Roberts S (2002) Human intervertebral disc aggrecan inhibits nerve growth in vitro. Arthritis Rheum 46: 2658-2664.

Khoury MK, Parker I, Aswad DW (2010) Acquisition of chemiluminescent signals from immunoblots with a digital single-lens reflex camera. Anal Biochem 397: 129131.

Kim NH, Kang ES, Han CD, Kim JD, Kim CH (1981) Auto-immune response in degenerated lumbar disk. Yonsei Med J 22: 26-32.

Le Maitre CL, Hoyland JA, Freemont AJ (2007) Catabolic cytokine expression in degenerate and herniated human intervertebral discs: IL-1beta and TNFalpha expression profile. Arthritis Res Ther 9: R77.

McCarron RF, Wimpee MW, Hudkins PG, Laros GS (1987) The inflammatory effect of nucleus pulposus. A possible element in the pathogenesis of low-back pain. Spine 12: 760-764.

Mihn DC, Kim TY (2011) Presence of various autoantibodies demonstrated by autoimmune target test in the sera of patients with degenerated and herniated intervertebral disc: comment on the article by Shamji et al. Arthritis Rheum 63: 862. 
Morgan K, Clague RB, Collins I, Ayad S, Phinn SD, Holt PJ (1987) Incidence of antibodies to native and denatured cartilage collagens (types II, IX, and XI) and to type I collagen in rheumatoid arthritis. Ann Rheum Dis 46: $902-907$.

Murai K, Sakai D, Nakamura Y, Nakai T, Igarashi T, Seo N, Murakami T, Kobayashi E, Mochida J (2010) Primary immune system responders to nucleus pulposus cells: evidence for immune response in disc herniation. Eur Cell Mater 19: 13-21.

Nandakumar KS, Bajtner E, Hill L, Bohm B, Rowley MJ, Burkhardt H, Holmdahl R (2008) Arthritogenic antibodies specific for a major type II collagen triplehelical epitope bind and destabilize cartilage independent of inflammation. Arthritis Rheum 58: 184-196.

Paesold G, Nerlich AG, Boos N (2007) Biological treatment strategies for disc degeneration: potentials and shortcomings. Eur Spine J 16: 447-468.

Patel AA, Spiker WR, Daubs M, Brodke D, CannonAlbright LA (2011) Evidence for an inherited predisposition to lumbar disc disease. J Bone Joint Surg Am 93: 225-229.

Pennington JB, McCarron RF, Laros GS (1988) Identification of $\mathrm{IgG}$ in the canine intervertebral disc. Spine 13: 909-912.

Raj PP (2008) Intervertebral disc: anatomy-physiologypathophysiology-treatment. Pain Pract 8: 18-44.

Rodrigues-Pinto R, Richardson SM, Hoyland JA (2013) Identification of novel nucleus pulposus markers: Interspecies variations and implications for cell-based therapiesfor intervertebral disc degeneration. Bone Joint Res 2: 169-178.

Roughley PJ, Melching LI, Heathfield TF, Pearce RH, Mort JS (2006) The structure and degradation of aggrecan in human intervertebral disc. Eur Spine J 15 Suppl 3: S326-332.

Satoh K, Konno S, Nishiyama K, Olmarker K, Kikuchi S (1999) Presence and distribution of antigen-antibody complexes in the herniated nucleus pulposus. Spine 24: 1980-1984.

Shamji MF, Setton LA, Jarvis W, So S, Chen J, Jing L, Bullock R, Isaacs RE, Brown C, Richardson WJ (2010) Proinflammatory cytokine expression profile in degenerated and herniated human intervertebral disc tissues. Arthritis Rheum 62: 1974-1982.

Spiliopoulou I, Korovessis P, Konstantinou D, Dimitracopoulos G (1994) IgG and IgM concentration in the prolapsed human intervertebral disc and sciatica etiology. Spine 19: 1320-1323.

Stefanakis M, Al-Abbasi M, Harding I, Pollintine P, Dolan P, Tarlton J, Adams MA (2012) Annulus fissures are mechanically and chemically conducive to the ingrowth of nerves and blood vessels. Spine 37: 1883-1891.

Strong JA, Xie W, Bataille FJ, Zhang JM (2013) Preclinical studies of low back pain. Mol Pain 9: 17.
Sztrolovics R, Alini M, Roughley PJ, Mort JS (1997) Aggrecan degradation in human intervertebral disc and articular cartilage. Biochem J 326: 235-241.

Urban JP, Roberts S (2003) Degeneration of the intervertebral disc. Arthritis Res Ther 5: 120-130.

\section{Discussion with Reviewers}

Reviewer I: Did these patients have any symptoms of an autoimmune disease or autoantibodies in the sera?

Authors: We did not have data for autoimmune diseases in the patients group. There are neither unique patient numbers nor central clinical data repositories in Switzerland, hence any option to check retrospectively.

Reviewer I: The presence of autoantibodies against matrix proteins has been demonstrated in arthritis and now in the disc. What are the implications in biological repair of these tissues?

Authors: As patients suffering from degenerative disc disease (DDD) could also have osteoarthritis (OA), further studies are needed to find unique and specific epitopes, which will bring diagnostic specificity and sensitivity. Beyond the question of diagnostics, the underlying implication is that patients having one type of degenerative problem, such as osteoarthritis, may be more prone to accelerated aging and degeneration of disc tissues after initial annulus fibrosus trauma.

Reviewer II: From a diagnostic viewpoint, the authors view the approach as providing a new approach to early diagnosis of disc disease. However, many patients who suffer from DDD also have OA, where there are raised levels of IgG collagen type II, MMP's and MMP degradation peptides. Thus, how can this approach be used diagnostically?

Authors: Clearly there are a number of questions to be answered before using these findings in diagnostics. It is possible that the auto-antibodies are the same across different cartilage/disc disease, and then no differential diagnosis would be possible. In the best case scenario, the discovery of epitopes specific for the immune response in the disc will be the important step towards the development of diagnostic tests for early stage disc degeneration. Early detection can permit one to treat conservatively the degeneration in the early stage, limit the autoimmune damage, and help tissue repair. Cell-based therapies or pharmaceutical interventions applied in very early stages of disc degeneration may have better outcomes, than when the degenerative changes are advanced. 